Aus der Chirurgischen Klinik der Universität in Bern.

(Direktor: Prof. Dr. Th. Kocher.)

\title{
Praktisches Gefäß zur völligen Entwässerung nicht gänzlich absoluten Alkohols.
}

Von Dr. Ludwig Oelsner.

In vorstehender Z Zeichnung dargestelltes Glasgefäß möchte ich besonders den mit Paraffin arbeitenden Histologen und pathologischen Anatomen empfehlen, da es:

1. vermöge seiner Konstrultion die Unterbringung einer größeren Anzahl verschiedener Objekte erlaubt und doch eine Verwechslungsmöglichkeit ausschließt. Denn die etwa einer und derselben Leiche entnommenen Stücke können in einem Glasschälchen auf dic obere Platte des Einsatzes $b$ gestellt werden;

2. weil jederzeit ohne Lüftung des Deckels sonst notwendiger. völliger wasserfreier Alkohol dem oberen Hahn des Gefäßes entnommen werden kann;

3. weil das im Einsatz $c$ untergebrachte, ausgeglühte Kupfersulfat durch Filtrierpapier so vom Alkohol abgeschlossen ist, daB bei reinlicher Hantierung während des Einfüllens ein Uebergehen des Pulvers in die Flüssigkeit nicht vorkommt und

4. weil der durch Vaselineumrandung in eine Nute eintauchende Deckel luftdicht schließt.

Zur gebrauchsfertigen Instandsetzung möchte ich folgendes Vorgehen anraten:

Die Seitenöffnungen des Einsatzes $c$ werden durch Aufbinden von Fließpapier verläßlich geschlossen, darauf das Gefäß vorsichtig bis zum oberen Rande mit ausgeglühtem Kupfersulfat gefüllt und auch die obere Oeffnung mit Fließpapier gedeckt. Nunmehr wird der so beschickte Einsatz auf den Boden des leeren Gefäßes $a$ gesetzt und dieses zunächst nur etwa $3 \mathrm{~cm}$ höher, als der obere Rand des Einsatzes $c$ reicht, mit Alkohol $(99 \%)$ gefüllt und so etwa eine halbe Stunde belassen. Erst dann wird der Einsatz $b$ an seine Stelle gebracht und Alkohol (99\%) soweit nachgefullt, bis er etwa $2 \mathrm{~cm}$ höher als die obere Platte desselben steht. Jetzt ist das Gefäß. dessen Deckelrand mit Vaseline eingerieben werden muB, gebrauchsfertig und liefert vermöge der großen Kupfersulfatmenge lange völlig wasserfreien Alkohol.

Erwähnt sei noch, daß die Hähne aus technischen Gründen nicht eingeschmolzen, sondern nur eingeschliffen sind, trotzdem aber völlig luftdicht schließen, wenn sie vor dem Einsetzen leicht mit Alkohol befeuchtet werden.

Der Apparat wird nach meinen Angabelı von der Firma M. Schaerer A.-G. in Bern gebaut. 